\title{
ПРОИЗВОДСТВО ОБЫСКА НА СТАДИИ ВОЗБУЖДЕНИЯ УГОЛОВНОГО ДЕЛА: ПРОБЛЕМЫ ПРОЦЕССУАЛЬНОГО ЗАКРЕПЛЕНИЯ И ПРАВОПРИМЕНЕНИЯ
}

\section{SEARCH AT THE STAGE OF CRIMINAL PROCEEDINGS: PROBLEMS OF PROCEDURAL FIXATION AND ENFORCEMENT}

N. Solovieva

A. Ilyasova

Summary. This article reveals the essence of the initial stage of criminal proceedings - the initiation of a criminal case, which is important for the implementation of fair justice in a criminal case. The article considers the normative fixing and regulation of the production of the investigative action - the «search» during the production of a procedural check on the report of a crime. Based on the current legislation of the Russian Federation, the norms of criminal procedure law governing the procedure for conducting investigative actions at the stage of initiating a criminal case were analyzed. As a result of the analysis, it was concluded that there are some urgent problems related to the application of law and law in conducting a «search» prior to initiating a criminal case, and some ways of solving the emerging problems were indicated in the form of making appropriate changes and additions to the norms of the criminal procedure legislation.

Keywords: stage of criminal proceedings, the concept of investigative action, search, seizure, inspection of the scene, obtaining samples for comparative research.

\author{
Соловьева Наталья Алексеевна \\ К.ю.н., Волгоградский государственный университет \\ solovievanataa@gmail.com \\ Ильясова Алтын Кожмуратовна \\ Аспирант, Волгоградский государственный \\ университет \\ ak_ilyasova@mail.ru
}

Аннотация. В настоящей статье раскрывается сущность первоначальной стадии уголовного судопроизводства — возбуждения уголовного дела, имеющей значение для осуществления справедливого правосудия по уголовному делу. Рассматривается нормативное закрепление и регулирование производства следственного действия - «обыска» при производстве процессуальной проверки по сообщению о преступлении. На основании действующего законодательства Российской Федерации были проанализированы нормы уголовно-процессуального права, регулирующие порядок производства следственных действий на стадии возбуждения уголовного дела. В результате проведенного анализа был сделан вывод о существовании некоторых актуальных проблем, связанных с применением права и закона при производстве «обыска» до возбуждения уголовного дела, а также были указаны некоторые пути решения возникающих проблем в виде внесения соответствующих изменений и дополнений в нормы уголовно-процессуального законодательства.

Ключевые слова: стадия возбуждения уголовного дела, понятие следственного действия, обыск, выемка, осмотр места происшествия, получение образцов для сравнительного исследования.

В настоящее время Уголовно-процессуальный кодекс Российской Федерации (далее - УПК РФ) является основным источником российского уголовно-процессуального законодательства, нормы которого регулируют процессуальный порядок производства обыска.

Однако, 04.03.2013 года был принят Федеральный закон № 23-Ф3 «О внесении изменений в статьи 62 и 303 Уголовного кодекса Российской Федерации и Уголовно-процессуальный кодекс Российской Федерации» (далее - Ф3 № 23). Данным Ф3 № 23 в нормы УПК РФ были внесены изменения, которые стали важной частью деятельности уполномоченных должностных лиц на стадии возбуждения уголовного дела [3].

Анализ практической деятельности, связанной с рассмотрение материала на стадии возбуждения уго- 
ловного дела, с момента принятия вышеуказанного Ф3 № 23, говорит о том, что указанный акт упростил процесс производства доследственной проверки. Однако, в то же время стоит отметить, что данные изменения оказали некоторое негативное воздействие на стадии расследования и рассмотрения уголовного дела, так как они требуют более детального юридического толкования.

К сожалению, в настоящем российском законодательстве существуют процессуальные проблемы, связанные с применением в практической деятельности норм, которые регламентируют порядок производства стадии возбуждения уголовного дела.

Конечно же, принятым Ф3 № 23 были внесены изменения в статью 144 УПК РФ, которые наделили уполномоченное лицо процессуальными полномочиями по истребованию предметов и документов, имеющих доказательственное значение при расследовании и рассмотрении уголовного дела. Однако, законодатель отметил, что данное действие возможно способами, установленными нормами уголовно-процессуального законодательства [4].

На наш взгляд, все изменения, внесенные в статью 144 УПК РФ, привели к возникновению и развитию некоторых проблем в правоприменительной практике стадии возбуждения уголовного дела, что в конечном итоге оказывают негативное воздействие на осуществление справедливого правосудия по расследованию и рассмотрению уголовного дела.

В то же время стоит отметить, что вышеуказанные изменения, внесенные в статью 144 УПК РФ, и предусматривающие возможность производства «изъятия» в порядке, установленном УПК РФ, в стадии возбуждения уголовного дела, привели некоторых ученых и правоприменителей к выводу о возможности проведения обыска в ходе производства проверки сообщения о преступлении [4].

Однако, с указанной позицией мы не можем согласиться, так как она приводит к возникновению противоречий между нормами УПК РФ, что в практической деятельности создают проблемы правоприменения на всех стадиях уголовного судопроизводства, в том числе и при производстве процессуальной проверки.

Анализ рассмотрения пути решения вышеуказанных проблем может быть проведен только после изучения норм, закрепленных УПК РФ, которые регламентируют порядок изъятия предметов и документов как самостоятельного источника собирания и оценки доказательств.
Нормы уголовно-процессуального права предусматривают четыре вида самостоятельных следственных действий, производство которых направлено на изъятие предметов. К данным действия относятся осмотр места происшествия, изъятие образцом для сравнительного исследования, выемка и обыск, производство которых регулируются отдельными нормами УПК РФ.

Важно отметить, что такие мероприятия, как осмотр места происшествия и получение образцов для сравнительного исследования, отдельно указаны в статье 144 УПК РФ, то есть законодатель разрешил при производстве процессуальной проверки по сообщению о преступлении, что нельзя сказать о производстве остальных действий, преследующих цель изъятия, на стадии возбуждения уголовного дела [5].

Кроме того, в нормах УПК РФ, понятие «изъятие» предметов и документов как самостоятельный способ собирания доказательств по уголовному делу отсутствует. Считаю, что данное обстоятельство связано с тем, что любое «изъятие» имеющих отношение к уголовному делу предметов и документов, может быть осуществлено только в рамках следственных действий, которые закреплены уголовно-процессуальным законом. На основании данных обстоятельств, включение в статью 144 УПК РФ термина «изъятия» привело некоторых ученых к выводу о возможности производства обыска до возбуждения уголовного дела, так как часть 1 статьи 144 УПК РФ предусматривает отсылочную формулировку - «В порядке, установленном настоящим Кодексом», которая и вызывает множество дискуссий по данному вопросу.

Возвращаясь к определению сущности и значения следственного действия, важно отметить, что таковым является мероприятие, которое может быть произведено в рамках расследуемого уголовного дела уполномоченными законом должностными лицами, которые направлены на сбор доказательств и установление обстоятельств [6].

Процессуальный порядок обыска регламентированы и закреплены в статье 182 УК РФ. В указанной статье, регламентирующей производство обыска, конкретно указано, что изымаемые предметы и документы должны «иметь значение для уголовного дела», что, несомненно, говорит о том, что производство данного действия возможно только в рамках проведения предварительного расследования.

Вся информация, полученная в стадии возбуждения уголовного дела, в последующем используются в качестве доказательств по уголовному делу. Однако, стоит отметить, что любое доказательство должно отвечать требованиям уголовно-процессуального законодатель- 
ства, в случае нарушения которого оно признается недопустимым, что оказывает негативное воздействие на осуществление справедливого правосудия [7].

Производство обыска в уголовном процессе является одним из видов следственных действий, в связи с чем, он может рассматриваться в качестве способа собирания доказательств. Следовательно, процессуальные проблемы обыска по уголовному делу могут быть связаны с совершенствованием норм его регулирования. При этом, стоит отметить, что статья 182 УПК РФ, в которой закреплены порядок и основания производства обыска, несколько раз подвергалась изменениям, которые можно охарактеризовать как усиление гарантий прав и законных интересов лиц, чьи интересы затрагиваются производимым действием - «обыском» [8].

Как было мною указано выше, процессуальное «изъятие» возможно только при производстве следственного действия, порядок которого регламентирован разделом УПК РФ с названием - «предварительное расследование». В свою очередь, в соответствии с частью 1 статьи 156 УПК РФ расследование проводится в форме следствия и в дознания, при этом оно начинается с момента возбуждения уголовного дела [4].

Кроме того, в анализируемой мною статье 182 УПК РФ четко указаны, основания производства обыска: либо по постановлению следователя, либо на основании судебного решения.

В тоже время, для более детального рассмотрения указанной проблемы необходимо обратится к процессуальному порядку проведения проверки в стадии возбуждения уголовного, производство которой установлено нормами УПК РФ.

В статье 144 УПК РФ указаны должностные лица, которые уполномочены проводить процессуальную проверку в стадии возбуждения уголовного дела, к которым относятся дознаватель, орган дознания, следователь, руководитель следственного органа. Данная норма УПК РФ свидетельствует о существующей процессуальной проблеме производства обыска в стадии возбуждения уголовного дела в том случае, если проверку проводит не следователь, а иное должностное лицо. В данной ситуации законодатель не указал варианты решения возникающих проблем, что в практической деятельности приводит к возникновению противоречивых ситуаций при расследовании и рассмотрении уголовного дела [9].

Кроме того, процессуальные проблемы могут возникнуть и при производстве осмотра места происшествия, которое в соответствии с действующим уголовно-процессуальным законодательством относится к средствам собирания доказательств, разрешенных на стадии процессуальной проверки. Прежде всего, эти проблемы касаются производства осмотра жилища против воли лиц, проживающих в нем.

В соответствии со статьей 25 Конституции Российской Федерации жилище неприкосновенно [10]. Данное обстоятельство также закреплено и в статье 12 УПК РФ, согласно которой осмотр жилища производится с согласия проживающих в нем лиц или на основании судебного постановления [4]. Что же делать, если согласия проживающих лиц нет, а осмотр жилища необходимо произвести с целью изъятия предметов и документов, имеющих значение для принятия решения по результатам рассмотрения материала процессуальной проверки.

К сожалению, нормы уголовно-процессуального законодательства не содержат решения в случае возникновения указанной проблемной ситуации. В данном случае, с целью изъятия соответствующих предметов и документов из жилища при производстве осмотра места происшествия при отсутствии согласия на данное действие проживающих в нем лиц, необходимо сначала возбудить уголовное дело, затем следователю или дознавателю вынести постановление о производстве обыска, в некоторых случаях получить судебное постановление, и только после данных действий изъять все, что имеет значение для уголовного дела [11]. Однако, производство многочисленных действий не будет способствовать осуществлению справедливого правосудия, так как все предметы и документы, имеющие значение для уголовного дела, могут быть уничтожены заинтересованным лицом, а виновное лицо может избежать уголовной ответственности.

С учетом возникающих проблем при производстве процессуальной проверки в стадии возбуждения уголовного дела, необходимо расширить перечень следственных действий, проводимых на указанном этапе уголовного судопроизводства. Однако, такие изменения в виде наделения уполномоченных лиц дополнительными функциями должны иметь разумные пределы, поскольку механизмы государственного принуждения могут применяться лишь со стадии производства предварительного расследования.

Проанализировав положения, предусмотренные статьей 144 и статьей 182 УПК РФ, можно говорить о наличии противоречий между ними, так как в соответствии с нормами уголовно-процессуального закона не позволяется производить следственные действия до возбуждения уголовного дела.

Считаем, что данные противоречия можно устранить путем внесения соответствующих изменений в статью 144 УПК РФ, указав на возможность производства 
обыска, в случае, если на то не будет требоваться соответствующее разрешение суда, либо четко прописать запрет на его производство в стадии возбуждения уголовного дела.

На основании вышеизложенного, можно сделать вывод о том, что до решения о возбуждении уголовного дела производство обыска недопустимо. Изъятие предметов и документов может быть произведено только теми способами, которые разрешены при рассмотрении материала процессуальной проверки.

Таким образом, в практической деятельности при расследовании и рассмотрении уголовного дела существует проблема применения нового федерального закона, согласно которого были внесены изменения в статью 144 УПК РФ.

Отсутствие точного и детального закрепления в российском уголовно-процессуальном законе нормы, регламентирующей процессуальный порядок производ- ства обыска в стадии возбуждения уголовного дела, приводит к возникновению противоречий при производстве процессуальной проверки по сообщению о преступлении. В то же время, неточное толкование закона приводит к получению интереса, который прямо противоречит нормам действующего законодательства [12].

Все проблемы, связанные с неправильным применением норм закона на стадии возбуждения уголовного дела, могут быть решены при условии внесения соответствующих изменений в уголовно-процессуальное законодательство нашего государства. Необходимо установить и закрепить исчерпывающие правила производства следственных действий и процессуальных мероприятий в стадии возбуждения уголовного дела, результаты которых будут применяться при осуществлении уголовного судопроизводства. Именно внесение вышеуказанных изменений в конечном итоге приведет к совершенствованию правового законодательства и способствованию развития в Российской Федерации правового государства.

\section{ЛИТЕРАТУРА}

1. Вандышев В. В. Уголовный процесс. Общая и Особенная части: учебник для юридических вузов и факультетов.—- М.: Контракт, Волтерс Клувер, 2010.— $720 \mathrm{C}$.

2. Быков В. 0 регламентации следственных действий // В. Быков, Н. Макаров // Российская юстиция.— 2005.— № 6, с. $16-18$.

3. Федеральный закон от 04.03.2013 года № 23-Ф3 «0 внесении изменений в статьи 62 и 303 Уголовного кодекса Российской Федерации и Уголовно-процессуального кодекса Российской Федерации».

4. Уголовно-процессуальный кодекс Российской Федерации: федеральный закон от 18 декабря 2001 года, № 174-Ф3, в редакции от 01.04 .2020 года.

5. Кальницкий, В.В. Истребование документов и предметов в стадии возбуждения уголовного дела // Законодательство и практика. - 2015.— № 2, c. 64-71.

6. Кальницкий В. В. Обоснованность производства следственных действий как предмет судебной оценки // Российская юстиция. - 2003. - № 2, с. 27-28.

7. Вицин С. Институт возбуждения дела в уголовном судопроизводстве // Российская юстиция.— М.— 2003.— № . 6. С. 54-56.

8. Ефимичев П.С. Новый Уголовно-процессуальный кодекс России и защита интересов личности и государства // Журнал российского права.— 2003.№ 2, с. 25-29.

9. Жамкова 0. Е. Некоторые проблемы реализации правовых норм при проверке сообщения о преступлении // Российский следователь. 一 2014 . № 9, с. 31.

10. Конституция Российской Федерации, принята всенародным голосованием 12.12.1993 года, (в редакции на 21.07.2014 года).

11. Судницын, А. Б. Истребование и изъятие предметов (документов) при проверке сообщения о преступлении // Вестник Сибирского юридического института ФСКН России. - 2016. — № 4 (25), с. 26-32.

12. Неганов Д.А., Юнусов А. А. Обеспечение законности в стадии возбуждения уголовного дела: // Вестник Казанского юридического института МВД России.— 2014. — № 2 (16), с. 71-78. 